\title{
Epidemiology and genotype 3 subtype dynamics of hepatitis E virus in Belgium, 2010 to 2017
}

Vanessa Suin ${ }^{1}$, Sofieke E Klamer ${ }^{2,3}$, Veronik Hutse ${ }^{1}$, Magali Wautier ${ }^{1}$, Marjorie Jacques ${ }^{1}$, Mona Abady ${ }^{1}$, Sophie Lamoral ${ }^{1}$, Vera Verburgh $^{1}$, Isabelle Thomas ${ }^{1}$, Bernard Brochier ${ }^{1}$, Lorenzo Subissi ${ }^{1,4}$, Steven Van Gucht ${ }^{1}$

1. National Reference Centre of Hepatitis Viruses, Viral Diseases, Infectious Diseases in Humans, Sciensano, Brussels, Belgium

2. Epidemiology of Infectious Diseases, Epidemiology and Public Health, Sciensano, Brussels, Belgium

3. European Program for Intervention Epidemiology Training, European Centre for Disease Prevention and Control, Stockholm, Sweden

4. European Program for Public Health Microbiology Training, European Centre for Disease Prevention and Control, Stockholm, Sweden

Correspondence: Steven Van Gucht (steven.vangucht@sciensano.be)

Citation style for this article:

Suin Vanessa, Klamer Sofieke E, Hutse Veronik, Wautier Magali, Jacques Marjorie, Abady Mona, Lamoral Sophie, Verburgh Vera, Thomas Isabelle, Brochier Bernard, Subissi Lorenzo, Van Gucht Steven. Epidemiology and genotype 3 subtype dynamics of hepatitis E virus in Belgium, 2010 to 2017 . Euro Surveill. 2019;24(10):pii=1800141. https://doi.org/10.2807/1560-7917.ES.2019.24.10.1800141

Background: Hepatitis E virus (HEV) is an emerging public health concern in high-income countries and can cause acute and chronic hepatitis. Reported numbers of indigenously acquired HEV infection have increased in the past decade in many European countries. Since 2010, the National Reference Centre (NRC) for Hepatitis Viruses has been testing samples of suspected hepatitis E cases in Belgium. Aim: In this surveillance report, we present the epidemiological trends of symptomatic HEV infections in Belgium, from the distribution by age, sex and geography to the molecular characterisation of the viral strains. Method: Serum samples of suspected cases sent to the NRC between 2010 and 2017 were analysed for the presence of HEV-specific IgM and RNA. Virus was sequenced for genotyping and phylogenetic analysis in all samples containing sufficient viral RNA. Results: The NRC reported an increase in the number of samples from suspected cases (from 309 to 2,663 per year) and in the number of laboratoryconfirmed hepatitis E cases (from 25 to 117 per year). Among 217 sequenced samples, $\mathbf{9 2 . 6 \%}$ were genotype 3 (HEV-3), followed by $6.5 \%$ of genotype 1 and $0.9 \%$ of genotype 4 . HEV-3 subtype viruses were mainly $3 \mathrm{f}$, $3 \mathrm{C}$ and $3 \mathrm{e}$. HEV- $3 \mathrm{f}$ was the most common subtype until 2015, while HEV-3c became the most common subtype in 2016 and 2017. Conclusion: The increasing trend of HEV diagnoses in Belgium may be largely explained by increased awareness and testing.

\section{Background}

Hepatitis E virus (HEV) infection is a worldwide cause of viral hepatitis. From its discovery in 1983 until recently, HEV was mainly considered as a waterborne disease endemic in low- and middle-income countries [1]. In the past decade, infections with indigenously acquired HEV have increasingly been reported in Europe, and the virus is thought to be transmitted, among other things, through undercooked deer, pork meat and shellfish [2]. Infections in humans are caused by genotypes 1 (HEV-1) and 2 (HEV-2), obligate human pathogens, and genotypes 3 (HEV-3), 4 (HEV-4) and 7 (HEV-7), mostly zoonotic. HEV-1 and HEV-2 detected in patients living in Europe are mostly travel-acquired infections, whereas HEV-4 is found mostly in South East Asia and China and HEV-3 is endemic worldwide [2].

Infections with HEV-3 and HEV-4 are often asymptomatic and otherwise typically cause mild to moderate disease. Rarely, the virus can provoke fulminant hepatitis in acute cases, and patients with underlying chronic liver disease are mainly at risk [3]. HEV can also cause severe liver damage in chronically infected patients and untreated patients with underlying diseases [3].

The seroprevalence in blood donors in countries of the European Union (EU) ranges from $2 \%$ to $50 \%$ [4-8]. The seroprevalence in some regions of Belgium was estimated around $15 \%$ [9]. Several studies in Europe have found up to $90 \% \mathrm{HEV}$-seropositive pigs on farms and HEV RNA was detected in up to $45 \%$ of pigs at slaughterhouses [10-13].

The epidemiology of HEV infections among the Belgian population remains poorly described. In 2010, the National Reference Centre (NRC) for Hepatitis Viruses was created at Sciensano by the national health authorities. The NRC is responsible for laboratory confirmation of suspected hepatitis E cases and genotyping of the causative virus in clinical samples. The aim of this study was to provide an overview of the epidemiological situation of HEV in Belgium from 2010 until 2017. 
Number of hepatitis E suspected cases, laboratory-confirmed cases (IgM+/PCR- and PCR+) and successfully sequenced cases per year, age group, sex and region of residence, Belgium, 2010-2017 ( $\mathrm{n}=8,941)$

\begin{tabular}{|c|c|c|c|c|c|c|c|c|}
\hline & Year & $\begin{array}{l}\text { Suspected } \\
\text { cases }\end{array}$ & $\begin{array}{c}\text { Column } \\
\text { percentages } \\
\text { of suspected } \\
\text { cases }^{\text {a }}\end{array}$ & $\begin{array}{l}\text { Confirmed } \\
\text { cases (IgM+/ } \\
\text { PCR-) }\end{array}$ & $\begin{array}{c}\text { Confirmed } \\
\text { cases } \\
(P C R+)\end{array}$ & $\begin{array}{l}\text { Sequenced } \\
\text { PCR+cases }\end{array}$ & $\begin{array}{l}\text { Total } \\
\text { confirmed } \\
\text { cases }\end{array}$ & $\begin{array}{c}\text { Column } \\
\text { percentages } \\
\text { of confirmed } \\
\text { cases }^{\text {a }}\end{array}$ \\
\hline \multirow{9}{*}{$\begin{array}{l}\text { Year of receipt at } \\
\text { National Reference } \\
\text { Centre }\end{array}$} & 2010 & 309 & 3.5 & 18 & 7 & 7 & 25 & 6.0 \\
\hline & 2011 & 466 & 5.2 & 16 & 17 & 17 & 33 & 7.9 \\
\hline & 2012 & 579 & 6.5 & 13 & 15 & 14 & 28 & 6.7 \\
\hline & 2013 & 687 & 7.7 & 13 & 19 & 15 & 32 & 7.7 \\
\hline & 2014 & 1,039 & 11.6 & 9 & 27 & 26 & 36 & 8.6 \\
\hline & 2015 & 1,384 & $15 \cdot 5$ & 24 & 40 & 24 & 64 & $15 \cdot 3$ \\
\hline & 2016 & 1,814 & 20.3 & 25 & 57 & 45 & 82 & 19.7 \\
\hline & 2017 & 2,663 & 29.8 & 36 & 81 & 69 & 117 & 28.1 \\
\hline & Total & 8,941 & 100.0 & 154 & 263 & 217 & 417 & 100.0 \\
\hline \multirow{5}{*}{ Age group } & $<20$ & 421 & $5 \cdot 9$ & 3 & 0 & 0 & 3 & 0.7 \\
\hline & $20-39$ & 1,813 & 25.6 & 35 & 36 & 32 & 71 & 17.2 \\
\hline & $40-64$ & 3,403 & 48.0 & 87 & 163 & 133 & 250 & 60.5 \\
\hline & $\geq 65$ & 1,448 & 20.4 & 28 & 61 & 49 & 89 & 21.5 \\
\hline & Missing & 1,856 & NA & 1 & 3 & 3 & 4 & NA \\
\hline \multirow{3}{*}{ Sex } & Male & 3,915 & 51.9 & 96 & 183 & 153 & 279 & 67.4 \\
\hline & Female & 3,634 & 48.1 & 56 & 79 & 62 & 135 & 32.6 \\
\hline & Missing & 1,392 & NA & 2 & 1 & 2 & 3 & NA \\
\hline \multirow{4}{*}{$\begin{array}{l}\text { Region of } \\
\text { residence }\end{array}$} & Flanders & 4,172 & 48.2 & 75 & 118 & 98 & 193 & 47.3 \\
\hline & Wallonia & 2,688 & 31.1 & 63 & 112 & 90 & 175 & 42.9 \\
\hline & Brussels & 1,791 & 20.7 & 12 & 28 & 27 & 40 & 9 \\
\hline & Missing & 290 & $\mathrm{NA}$ & 4 & 5 & 2 & 9 & NA \\
\hline
\end{tabular}

IgM+: IgM-positive; NA: not applicable; PCR+: PCR-positive; PCR-: PCR-negative.

a Column percentages were calculated excluding the records with missing values for the analysed characteristic.

\section{Methods}

\section{Patient samples}

Suspected cases were defined as any person whose sample was sent to the NRC for HEV testing. Confirmed cases were defined as persons with an IgM- and/or RT-qPCR-positive sample.

This study included all laboratory tests performed on clinical samples of suspected cases that were submitted to the NRC for HEV diagnosis between 1 January 2010 and 31 December 2017. Serum samples originated from hospitals and peripheral laboratories throughout Belgium and were submitted by general practitioners or internal medicine specialists. Belgian clinicians can send a clinical sample to the NRC, either to obtain a primary diagnosis or to obtain a confirmation diagnosis for HEV serology and/or HEV RNA. Similarly, primary laboratories are asked to send all positive and equivocal samples to the NRC for confirmation of the diagnosis, genotyping and epidemiological purpose. Primary laboratories may also send suspected samples to obtain a primary diagnosis when HEV serology and/ or HEV RNA testing is not routinely performed in their laboratory. The submission of samples to the NRC is voluntary. The costs of the confirmation diagnosis and genotyping are covered by the federal NRC programme. We quantified the proportion of clinical laboratories that send samples for HEV testing to the NRC. Overall, $84 \%$ of the laboratories ( $86 \%$ of hospital laboratories and $83 \%$ of primary care laboratories) participated at least once during the study period.

We assumed that all samples received by the NRC were from patients who presented with clinical signs of viral hepatitis and/or increased biochemical liver values, or from patients with increased risk at developing disease and/or complications when infected (e.g. liver transplant patients). The following data were collected for each sample on the request form: requested analysis (IgG, IgM, qPCR or sequencing), date of birth, sex, postal code, hospitalisation status, travel history, clinical data, sampling date and referring laboratory and/ or clinician. HEV serology and RT-qPCR were performed upon request and when sufficient sample volume was present. RT-qPCR was performed routinely on all IgMpositive samples. Cases were defined as laboratoryconfirmed if the serum submitted to the NRC for HEV diagnostics was positive for HEV IgM and/or RNA. 
Number of hepatitis E suspected samples, laboratory-confirmed cases and confirmation ratio per month, Belgium, 2010$2017(\mathrm{n}=8,941)$

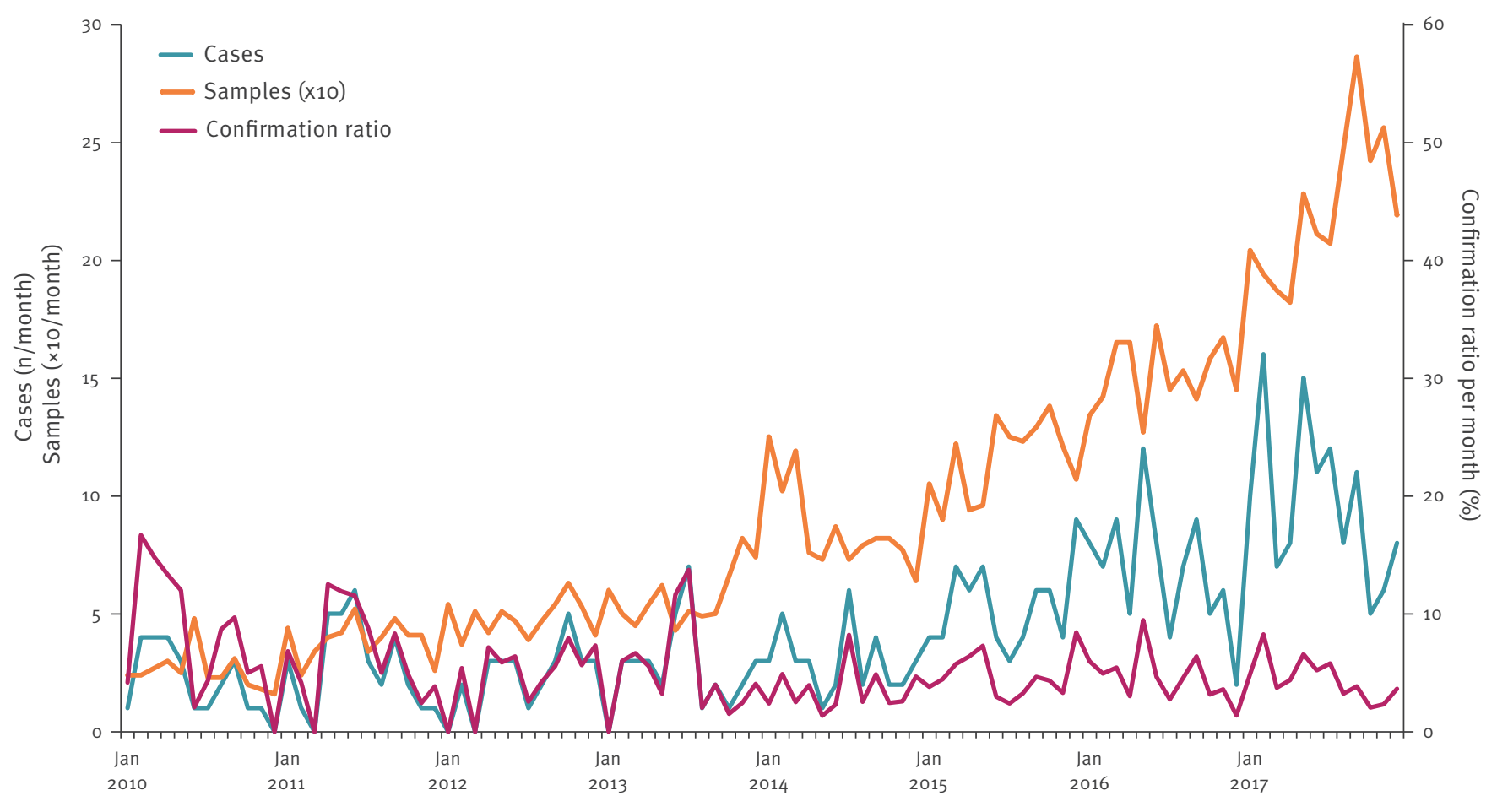

Hepatitis E virus serology

HEV serology (IgM) was performed using the commercial enzyme immunoassay RecomWell HEV IgG/M (Mikrogen Diagnostik, Germany; specificity: $98.6 \%$, sensitivity: $98.9 \%$ ) from 2010 to 2015 and the Wantai IgM assay (Sanbio, Japan; specificity: 95.3-100\%, sensitivity: $97.1 \%$ ) from 2016 to 2017 . Signal to cut-off ratios were interpreted as prescribed. All positive and equivocal results obtained with the Mikrogen ELISA were considered positive only when confirmed by Western blot analysis (RecomBlot HEV IgG/M; Mikrogen Diagnostik, Germany). All equivocal results obtained with the Wantai IgM ELISA were considered positive only when the samples tested positive a second time. Positive and negative controls from the kits and an external positive quality control were included in each assay. The external positive control for HEV IgM consisted of a pool of several positive anti-HEV IgM sera collected in the past. All positive HEV IgM were also analysed by qPCR.

\section{Detection and sequencing of hepatitis E virus RNA}

HEV RNA was extracted from serum samples using the QIAamp Viral RNA mini kit (Qiagen, Germany). Specific HEV RNA was analysed using the commercial RealStar HEV qRT-PCR Kit 1.0 (Altona Diagnostics, Germany). For each qRT-PCR assay, several controls were analysed in duplicate: a positive control from the Real Star kit, an external positive and negative control and an extraction control to identify possible qRT-PCR inhibition and to confirm the integrity of the reagents of the kit. The external positive control used was the World Health Organization standard for HEV RNA nucleic acid amplification $10 \times$ diluted (National Institute for Biological Standards and Control, England). The external negative control used was RNase-free water sample. Results were interpreted according to the manufacturer's protocol. The extraction control was RNase $\mathrm{P}$ detection with primers from Hummel et al. [14].

In case of positive qRT-PCR (from 2010 to 2016), HEV was genotyped according to a protocol adapted from Huang et al. [15]. Since HEV strains are genetically heterogenic, a universal HEV nested RT-PCR assay with degenerated HEV primers was developed to detect genetically divergent strains of HEV. Two sets of degenerated HEV primers were used for the universal nested RT-PCR assay: external primer set $3156 \mathrm{~N}$ (forward, 5'-AATTATGCC(T)CAGAC(T)CGG(A)GTG-3') and 3157N (reverse, 5'-CCCTTA(G)TCC(T)TGCTGA(C)GCATTCTC-3') and internal primer set $3158 \mathrm{~N}$ (forward, 5'-GT(A) ATGCTT(C)TGCATA(T)CATGGCT-3') and 3159N (reverse, 5'-AGCCGACGAAATCAA TTCTGC-3'). The expected product of the universal nested RT-PCR consisted of $348 \mathrm{bp}$ in the ORF2 region of the HEV genome [15]. From 2017 onwards, a more sensitive genotyping protocol was used as described by Boxman et al. [16].

Positive amplicons were sequenced using the big dye terminator v.3.1 cycle sequencing kit (Applied Biosystems, United States (US)) and analysed on an 
TABLE 2

Hepatitis E virus infections by genotype, Belgium, 2010-2017 $(\mathrm{n}=217)$

\begin{tabular}{|l|c|c|c|c|c|c|c|c|c|}
\hline Genotype & 2010 & 2011 & 2012 & 2013 & 2014 & 2015 & 2016 & 2017 & Total \\
\hline HEV-1 & 2 & 3 & 2 & 0 & 0 & 2 & 4 & 1 & 14 \\
\hline HEV-3 & 5 & 14 & 10 & 15 & 26 & 22 & 41 & 68 & 201 \\
\hline HEV-4 & 0 & 0 & 2 & 0 & 0 & 0 & 0 & 0 & 2 \\
\hline
\end{tabular}

TABLE 3

Hepatitis E virus genotype 3 infections by subtype, Belgium, 2010-2017 ( $=201$ )

\begin{tabular}{|l|c|c|c|c|c|c|c|c|c|}
\hline Genotype & 2010 & 2011 & 2012 & 2013 & 2014 & 2015 & 2016 & 2017 & Total \\
\hline HEV-3a & 0 & 0 & 0 & 0 & 0 & 2 & 0 & 0 & 2 \\
\hline HEV-3C & 1 & 2 & 0 & 4 & 9 & 9 & 20 & 35 & 80 \\
\hline HEV-33 & 1 & 2 & 1 & 3 & 2 & 0 & 1 & 3 & 13 \\
\hline HEV-3f & 3 & 10 & 9 & 8 & 13 & 11 & 19 & 29 & 102 \\
\hline HEV-3h & 0 & 0 & 0 & 0 & 1 & 0 & 1 & 0 & 2 \\
\hline HEV-3i & 0 & 0 & 0 & 0 & 0 & 0 & 0 & 1 & 1 \\
\hline HEV-3ra & 0 & 0 & 0 & 0 & 1 & 0 & 0 & 0 & 1 \\
\hline
\end{tabular}

ABI Prism 3130 Genetic Analyzer (Applied Biosystems, US). Sequences of PCR products were determined for both DNA strands and were uploaded to HEVnet (https://www.rivm.nl/en/hevnet), an EU database for HEV sequences hosted by the Dutch National Institute for Public Health and the Environment.

\section{Data analysis}

The number of suspected and confirmed cases per year and month was based on the receipt date of the sample at the NRC. Multiple samples from the same patient in the same year were reduced to a single record. The confirmation ratio was calculated as the confirmed cases divided by the suspected cases within the same period. Trends over time of suspected and confirmed cases were modelled with linear regression analysis. The slope coefficients of the standardised data for suspected and confirmed cases were compared in linear regression analysis. Wilson 95\% confidence intervals (CI) were calculated for proportions and Pearson's chisquared test was used to compare proportions. STATA 14.0 and SAS were used for the statistical analyses.

\section{Phylogenetic analysis}

Phylogenetic trees included the 348 bp sequences of the ORF2 genes characterised at the NRC in patient's clinical samples, the HEV reference strains from Smith et al. [17] and selected animal and human HEV sequences available in GenBank. Sequence comparison, alignments and phylogenetic trees were realised using CLC main workbench 7.8.1 and MEGA 7 software [18]. Sequences differing at more than $1 \%$ of nucleotide positions were analysed using the maximum likelihood method based on the Tamura-Nei model using MEGA 7 software. The confidence values of the internal nodes were calculated by performing 1,000 bootstrap analyses. When the sequences most closely related to Belgian isolates were reference strains, an indication of nucleotide $p$-distance was reported.

\section{Ethical statement}

The study is covered by the official mandate of the National Reference Centre for Hepatitis Viruses to collect and analyse epidemiological and clinical data of hepatitis $E$ cases in Belgium as part of the national surveillance plan and promotion of public health. Considering the retrospective and non-interventional nature of the study, approval of an ethics commission or individual informed consent were not required, in agreement with the Belgian Law from 7 May 2004 concerning experiments on people.

\section{Results}

\section{Characteristics of hepatitis E patients}

In 2010, 25 of 309 tested samples (8.1\%) were from laboratory-confirmed hepatitis E cases, whereas in 2017 , 117 of 2,663 tested samples (4.4\%) were from laboratory-confirmed cases (Table 1). The overall confirmation ratio was stable between 2012 and 2017, ranging between $3.5 \%$ and $4.8 \%$. Overall, $37 \%$ of the 417 confirmed cases were only IgM-positive (and PCR-negative) while the remaining $63 \%$ of cases were PCR-positive (and IgM-positive or -negative; Table 1). Hepatitis E was mainly detected in 40-64 year-old adults and rarely in children and adolescents. Men were more affected 


\section{FIGURE 2}

Phylogenetic analysis of hepatitis E virus genotype 3 isolates, Belgium, 2010-2017 ( $\mathrm{n}=186$ human sequences)

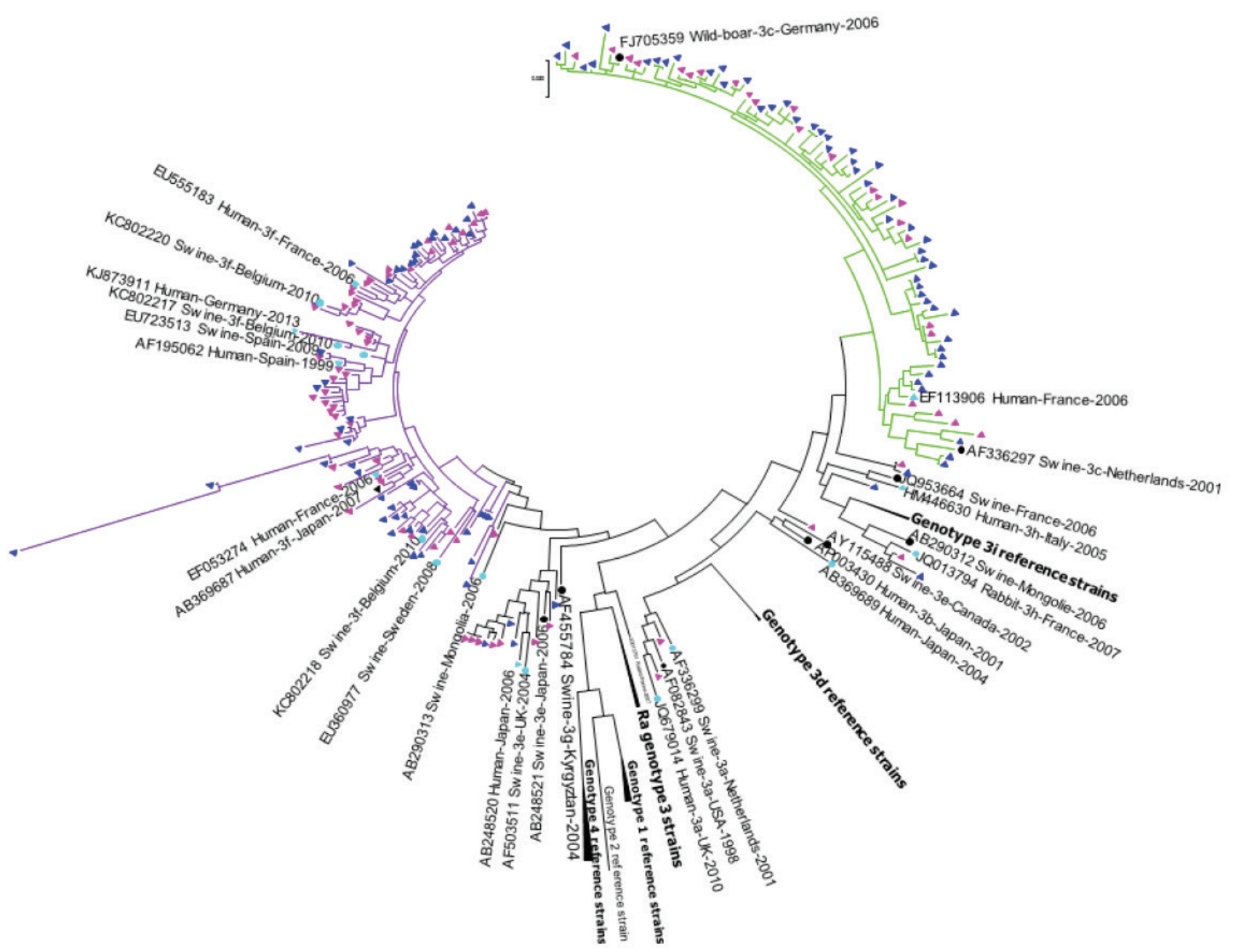

HEV: hepatitis E virus.

Maximum-likelihood phylogenetic tree of a $348 \mathrm{bp}$ fragment from open reading frame 2. Genetic distances were calculated using the Tamura Nei model. GenBank accession numbers are shown for each HEV reference strain used in the phylogenetic analysis and are noted as follows: Accession number_Host-HEV subtype-Country-Year. Triangles represent human HEV sequences and circles animal sequences.

Green lines: all HEV-3c isolates; purple lines: all HEV-3f isolates. Rose symbols: HEV sequences from 2010 to 2015 ; dark blue symbols: HEV sequences from 2016 to 2017; black symbols: HEV reference strains according to Smith et al. [17]; light blue symbols: other human and animal HEV sequences.

than women in this age group (Table 1). Overall, the annual sex ratio (male/female) varied between 1.6 and 4.0 during the study period. When looking at the three geographical regions of Belgium (Flanders, Wallonia and Brussels), inhabitants of Flanders represented $48 \%(4,172 / 8,651)$ of the suspected cases and $47 \%(193 / 408)$ of confirmed cases, while inhabitants of Wallonia represented $31 \%(2,688 / 8,651)$ of suspected samples and $43 \%(175 / 408)$ of confirmed cases. Finally, inhabitants of Brussels represented $21 \%$ $(1,791 / 8,651)$ of the suspected cases and $10 \%(40 / 408)$ of confirmed cases (Table 1). Relative to the population, Wallonia was slightly oversampled compared with Flanders, whereas the number of tests relative to the population size was almost twice as high in Brussels (data not shown).

The number of suspected cases, laboratory-confirmed cases and the confirmation ratio per month are shown in Figure 1. The number of suspected and confirmed cases increased significantly over time between 2010 and 2017 in the linear regression (both p values<0.001). The slope coefficients of both standardised trends were not significantly different.

Genotyping and phylogenetic analysis

Genotyping was successful for 217 of 263 PCR-positive samples $(82.5 \%)$, which represented $52.0 \%$ of all 


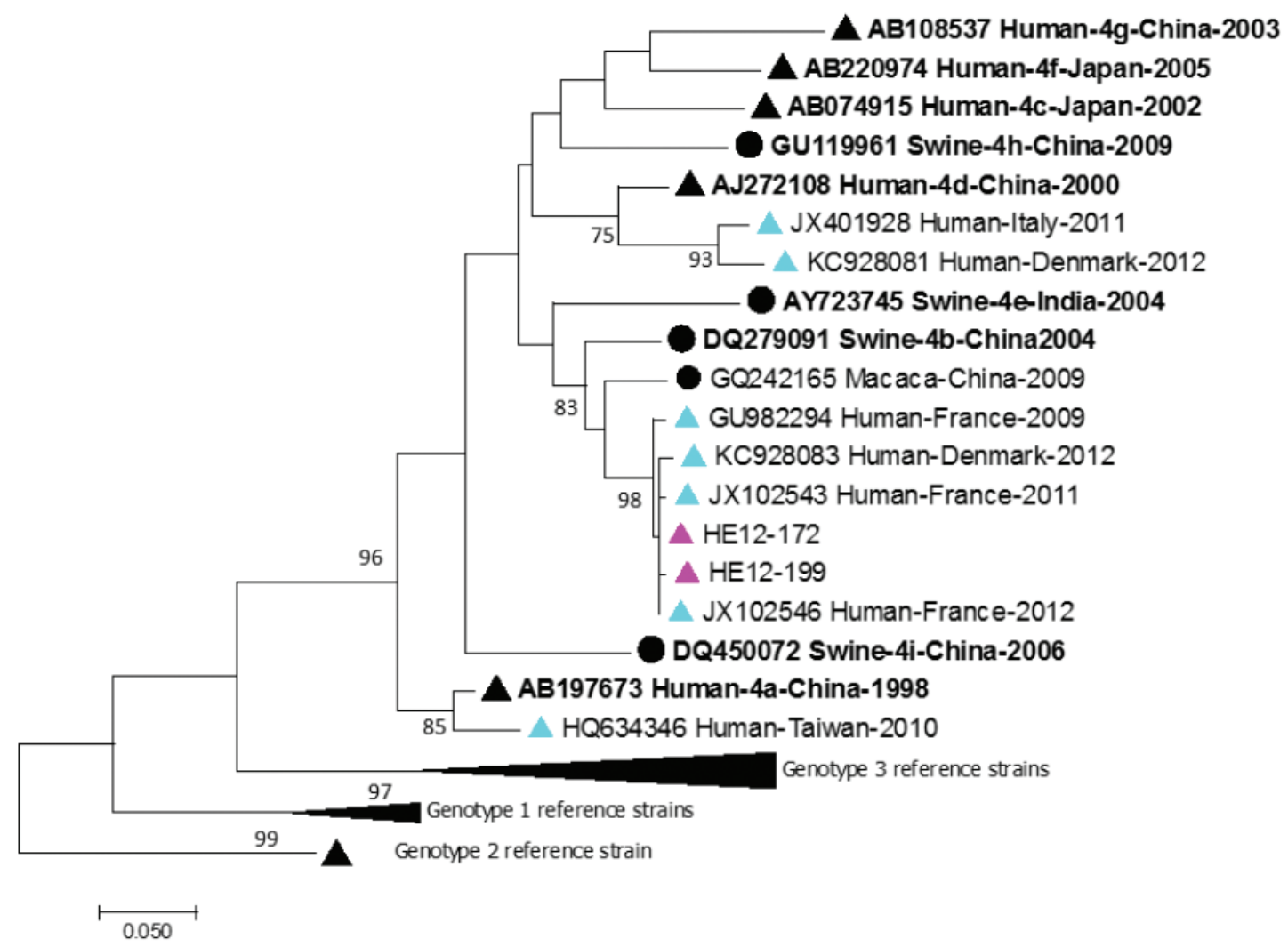

HEV: hepatitis E virus.

Maximum-likelihood phylogenetic tree of a $348 \mathrm{bp}$ fragment from open reading frame 2. Genetic distances were calculated using the Tamura Nei model. Only bootstrap values 70 are reported. GenBank accession numbers are shown for each HEV reference strain used in the phylogenetic analysis and are noted as follows: Accession number_Host-HEV subtype-Country-Year. Triangles represent human HEV sequences and circles animal sequences.

Rose symbols: 2012 Belgian HEV-4 sequences; black symbols: HEV reference strains according to Smith et al. [17]; light blue symbols: other human and animal HEV sequences.

laboratory-confirmed cases (217/417; Table 1). HEV-3 was the most common genotype (92.6\%, $\mathrm{n}=201)$, followed by HEV-1 $(6.5 \%, n=14)$ and HEV-4 (0.9\%, $\mathrm{n}=2$; Table 2). For three confirmed cases, a recent travel history outside Europe was reported and they were all infected with HEV-1. Among the $201 \mathrm{HEV}-3$ sequences, subtypes $3 f(50.7 \%, n=102)$ and $3 c(39.8 \%, n=80)$ were found most often, followed by 3 e $(6.4 \%, n=13)$, whereas $3 a$ and 3 h with $1.0 \%(n=2)$ and $1.5 \%(n=3)$, respectively, were rarely detected (Table 3 ). During the period from 2010 to 2015 , 3 f accounted for $58.7 \%$ of all genotype 3 sequences, while $3 c$ accounted for $27.2 \%$ and other HEV-3 subtypes for $14.1 \%$. These proportions changed during the period from 2016 and 2017: $3 c$ increased to account for $50.5 \%$, 3f decreased to 44.0\% and other HEV-3 subtypes decreased to $5.5 \%$ (chi-squared $p$ value $<0.001$, Table 3 ).
Some Belgian HEV-3C strains clustered with previously described European or American human or swine HEV isolates [19]. Belgian HEV-3f isolates were closely related to previously described swine or human strains from European countries and Japan (2007). Both Belgian HEV-4 isolates from 2012 were most closely related to human HEV-4 strains from France isolated in 2011 and 2012 (Figure 3).

Geographical distribution of hepatitis E virusconfirmed cases

For further analysis, known HEV-1 and HEV-4 cases were excluded from the confirmed cases. The resulting nation-wide $\mathrm{HEV}-3$ confirmation ratio was highest in 2010 (7.5\%), lowest in 2014 (3.4\%) and ranged between 4.0 and $4.5 \%$ for the period from 2015 to 2017 . A significant difference in the confirmation ratio was 
TABLE 4

Number of tested samples and confirmed cases, excluding all known HEV-1 and HEV-4 cases, in the regions Flanders, Wallonia and Brussels per year, Belgium, 2010-2017 $(n=8,923)$

\begin{tabular}{|c|c|c|c|c|c|}
\hline Region of residence & Year & $\begin{array}{c}\text { Number of tested } \\
\text { samples }\end{array}$ & $\begin{array}{l}\text { Confirmed cases } \\
\text { (excluding HEV-1 and } \\
\text { HEV-4) }\end{array}$ & $\begin{array}{l}\text { Proportion confirmed } \\
(\%)\end{array}$ & $\begin{array}{l}95 \% \text { confidence } \\
\text { interval }\end{array}$ \\
\hline \multirow{8}{*}{ Flanders } & 2010 & 135 & 11 & 8.1 & $4.6-14.0$ \\
\hline & 2011 & 214 & 18 & 8.4 & $5.4-12.9$ \\
\hline & 2012 & 254 & 10 & 3.9 & $2.2-7.1$ \\
\hline & 2013 & 315 & 15 & 4.8 & $2.9-7.7$ \\
\hline & 2014 & 443 & 17 & 3.8 & $2.4-6.1$ \\
\hline & 2015 & 671 & 30 & $4 \cdot 5$ & $3.2-6.3$ \\
\hline & 2016 & 957 & 32 & 3.3 & $2.4-4 \cdot 7$ \\
\hline & 2017 & 1,176 & 53 & $4 \cdot 5$ & $3.2-6.3$ \\
\hline \multirow{8}{*}{ Wallonia } & 2010 & 122 & 10 & 8.2 & $4 \cdot 5-14 \cdot 4$ \\
\hline & 2011 & 147 & 12 & 8.2 & $4 \cdot 7-13 \cdot 7$ \\
\hline & 2012 & 201 & 14 & 7.0 & $4.2-11.4$ \\
\hline & 2013 & 196 & 16 & 8.2 & $5.1-12.8$ \\
\hline & 2014 & 301 & 15 & 5.0 & $3.0-8.1$ \\
\hline & 2015 & 402 & 27 & 6.7 & $4.7-9.6$ \\
\hline & 2016 & 511 & 34 & 6.7 & $4.8-9.2$ \\
\hline & 2017 & 805 & 44 & 5.5 & $4.1-7.3$ \\
\hline \multirow{8}{*}{ Brussels } & 2010 & 45 & 2 & $4 \cdot 4$ & $1.2-14.8$ \\
\hline & 2011 & 91 & 0 & 0.0 & $0.0-4.1$ \\
\hline & 2012 & 97 & 0 & 0.0 & $0.0-3.8$ \\
\hline & 2013 & 155 & 1 & 0.6 & $0.1-3.6$ \\
\hline & 2014 & 278 & 3 & 1.1 & $0.4-3.1$ \\
\hline & 2015 & 280 & 5 & 1.8 & $0.8-4.1$ \\
\hline & 2016 & 276 & 7 & 2.5 & $1.2-5.1$ \\
\hline & 2017 & 561 & 14 & 2.5 & $1.5-4.1$ \\
\hline \multirow{8}{*}{ Overallc } & 2010 & 307 & 23 & 7.5 & $4.8-11.0$ \\
\hline & 2011 & 463 & 30 & 6.5 & $4.4-9.1$ \\
\hline & 2012 & 575 & 24 & 4.2 & $2.7-6.2$ \\
\hline & 2013 & 687 & 32 & $4 \cdot 7$ & $3.2-6.5$ \\
\hline & 2014 & 1,039 & 35 & $3.4^{d}$ & $2.4-4 \cdot 7$ \\
\hline & 2015 & 1,382 & 62 & $4 \cdot 5$ & $3 \cdot 5-5 \cdot 7$ \\
\hline & 2016 & 1,809 & 73 & $4.0^{d}$ & $3.2-5.1$ \\
\hline & 2017 & 2,661 & 111 & $4.2^{d}$ & $3.4-5.0$ \\
\hline
\end{tabular}

a Excluding tested samples identified as HEV-1 and HEV-4.

b The confirmed cases that were not sequenced are included.

c Including 290 suspected cases with unknown region of residence spread over all years.

${ }^{d}$ Including nine confirmed cases with unknown region of residence spread over the years 2014,2016 and 2017.

only detected between the years $2010(95 \% \mathrm{Cl}: 4.8-$ 11.0) and 2014 (95\% Cl: 2.4-4.7; Table 4).

\section{Discussion}

The epidemiology of symptomatic HEV infection among people in Belgium is poorly described. Here, we provide an overview of the epidemiological situation of HEV in laboratory-confirmed patients and an analysis of strains circulating in Belgium between 2010 and 2017. We report an increase in the number of hepatitis E cases diagnosed at the NRC and a simultaneous increase in the number of tested samples. Based on our data, increased awareness and testing are the most likely contributors to the rise in the number of confirmed hepatitis E cases in Belgium. The number of reported confirmed hepatitis $\mathrm{E}$ cases consistently and simultaneously increased in many European countries during the last decade $[20,21]$. However, a recent study from Germany showed a slight decline in seroprevalence between 1998 and 2010, suggesting a decrease in the seroincidence during this period [22]. As expected, we found that men represented two thirds of the confirmed cases and the median age wasmore than 50 years. In Belgium, it is unclear why the highest number 
of cases relative to the number of tested samples were recorded in the Walloon region. Interestingly, a nationwide survey of HEV infections among blood donors in France found the north-east region close to the border with the Walloon region as one of the three areas of France with highest HEV seroprevalence [23]. In Brussels, the number of tests relative to the population size was almost double compared with the two other regions (where they were roughly comparable, data not shown). This might be explained by higher awareness among physicians or possibly the different population characteristics (e.g. higher incidence of viral hepatitis of the types A, B and C).

Phylogenetic analysis identified HEV-3 as the main circulating genotype in Belgium, while HEV-1 and HEV-4 were detected sporadically. For most cases with HEV-3 infection, information about travel history was missing and it was thus not possible to exclude that the infection was acquired abroad. However, our molecular data suggest that the HEV-3 infections were acquired in Europe.

In England and Wales, the Netherlands and Germany, the most commonly identified HEV-3 subtype is 3 , while the main one in Spain and France is $3 f$ [20]. In Belgium, $3 \mathrm{f}$ was the most commonly identified subtype until 2015, whereas $3 \mathrm{C}$ was the most commonly identified subtype in 2016 and 2017. This trend was also observed in England and Wales between 2010 and 2012, where the number of subtype $3 c$ strains identified from patients exceeded that of subtypes $3 e, 3 f$ and 39 [24]. HEV-3 strains from cases in Belgium tend to be closely related to the strains present in European pigs and wildlife (wild boar and deer). Products such as raw pork liver, raw pork sausages and pork pâté have been identified previously as likely sources of transmission [25-27]. Interestingly, all swine HEV sequences obtained by Thiry et al. in 2014 from Belgian swine sera belonged to HEV-3f, similar to the dominant subtype found in human cases until 2015 in this study [10].

One of the limitations of this study is that we used IgM data from two different ELISA assays with different specificity and sensitivity. The fact that the proportion of IgM-positive to PCR-negative cases did not increase after the introduction of the Wantai assay makes us confident that this switch has not considerably affected our diagnoses over the years. An additional limitation of this study is that the submission of samples to the NRC is voluntary, but over the years, $84 \%$ of all Belgian diagnostic centres participated to this surveillance system at least once. Furthermore, we had limited clinical and epidemiological data available from our cases (e.g. travel history and underlying comorbidities). The asymptomatic or mild presentation of most HEV infections implies that laboratory-confirmed cases are not representative of all HEV infections. Unfortunately, recent nation-wide HEV seroprevalence studies are lacking, which would have completed the epidemiological observations.

\section{Conclusion}

We observed an increasing trend of HEV-confirmed cases over the study period, and a simultaneous increase in the number of suspected samples, with a tendency of higher confirmation ratios observed for the south of Belgium (Wallonia) compared with the other regions. We think that this increasing trend is mainly due to increased awareness and testing because of the simultaneous increase in the number of suspected samples. We cannot exclude minor dynamics in disease burden over the past years, but a pronounced recent increase in the overall disease burden may be excluded because the confirmation ratio has been stable since 2012. The regional differences in confirmation ratios may guide further investigations about exposures (e.g. food habits) and risk factors (e.g. liver disease).

The majority of the cases were typed as HEV-3, of the subtypes $3 f$ and $3 c$. The changing epidemiology of HEV-3C may warrant further investigation, e.g. to study the presence of this subtype among livestock and wild boars. More studies on the epidemiology and subtypes of $\mathrm{HEV}$ in animal reservoirs and in food may identify transmission routes in Belgium. Consumption of products containing raw or undercooked pig liver, blood and meat products may represent the major risk factors for human HEV infections, and adaptations of food production processes (e.g. heat treatment) are highly recommended in order to improve food safety.

\section{Acknowledgements}

We thank Cyril Barbezange for critical reading of the manuscript. The National Reference Centre of Hepatitis Viruses of Sciensano is partially supported by the Belgian Ministry of Social Affairs through a fund from the National Institute for Health and Disability Insurance (RIZIV-INAMI).

Funding: This study was a retrospective analysis of routinely collected data, within the national NRC program funded by the National Institute for Health and Disability Insurance (RIZIV-INAMI).

\section{Conflict of interest}

None declared.

\section{Authors' contributions}

VS conceived the study, analysed data, designed the figures and wrote the manuscript. SK analysed data, helped in data interpretation and figure design and revised the manuscript. VH conceived the study. MW conceived the study. MJ performed ELISA tests. MA performed RT-PCR tests and genotyping analysis. SL performed RT-PCR and genotyping analysis. VV performed ELISA tests. IT conceived the study. BB conceived the study. LS analysed data, helped in data interpretation and figure design and wrote the manuscript. SVG conceived the study and wrote the manuscript. 


\section{References}

1. Dalton HR, Stableforth W, Hazeldine S, Thurairajah P, Ramnarace R, Warshow U, et al. Autochthonous hepatitis E in Southwest England: a comparison with hepatitis A. Eur J Clin Microbiol Infect Dis. 2008;27(7):579-85. https://doi. org/10.1007/s10096-008-0480-Z PMID: 18299907

2. Kamar N, Izopet J, Pavio N, Aggarwal R, Labrique A, Wedemeyer $\mathrm{H}$, et al. Hepatitis E virus infection. Nat Rev Dis Primers. 2017;3:17086. https://doi.org/10.1038/nrdp.2017.86 PMID: 29154369

3. Nimgaonkar I, Ding Q, Schwartz RE, Ploss A. Hepatitis E virus: advances and challenges. Nat Rev Gastroenterol Hepatol. 2018;15(2):96-110. https://doi.org/10.1038/nrgastro.2017.150 PMID: 29162935

4. Mansuy JM, Saune K, Rech H, Abravanel F, Mengelle C, L Homme S, et al. Seroprevalence in blood donors reveals widespread, multi-source exposure to hepatitis E virus, southern France, October 2011. Euro Surveill. 2015;20(19):2734. https://doi.org/10.2807/1560-7917.ES2015.20.19.21127 PMID: 25990359

5. Lucarelli C, Spada E, Taliani G, Chionne P, Madonna E, Marcantonio C, et al. High prevalence of anti-hepatitis E virus antibodies among blood donors in central Italy, February to March 2014. Euro Surveill. 2016;21(30):30299. https://doi. org/10.2807/1560-7917.ES.2016.21.30.30299 PMID: 27494608

6. Domanović D, Tedder R, Blümel J, Zaaijer H, Gallian P, Niederhauser $C$, et al. Hepatitis E and blood donation safety in selected European countries: a shift to screening? Euro Surveill. 2017;22(16):30514. https://doi.org/10.2807/15607917.ES.2017.22.16.30514 PMID: 28449730

7. Hartl J, Otto B, Madden RG, Webb G, Woolson KL, Kriston L, et al. Hepatitis E seroprevalence in Europe: a meta-analysis. Viruses. 2016;8(8):E211. https://doi.org/10.3390/v8080211 PMID: 27509518

8. Mansuy JM, Gallian P, Dimeglio C, Saune K, Arnaud C, Pelletier $B$, et al. A nationwide survey of hepatitis E viral infection in French blood donors. Hepatology. 2016;63(4):1145-54. https:// doi.org/10.1002/hep.28436 PMID: 27008201

9. Van Hoecke F, Van Maerken T, De Boulle M, Geerts A, Vlierberghe V, Colle I, et al. Hepatitis E seroprevalence in east and west Flanders, Belgium. Acta Gastroenterol Belg. 2012;75(3):322-4. PMID: 23082702

10. Thiry D, Mauroy A, Saegerman C, Thomas I, Wautier M, Miry C, et al. Estimation of hepatitis $\mathrm{E}$ virus (HEV) pig seroprevalence using ELISA and Western blot and comparison between human and pig HEV sequences in Belgium. Vet Microbiol. 2014;172(34):407-14. https://doi.org/10.1016/j.vetmic.2014.06.004 PMID: 24975642

11. Grierson S, Heaney J, Cheney T, Morgan D, Wyllie S, Powell L, et al. Prevalence of hepatitis $\mathrm{E}$ Virus infection in pigs at the time of slaughter, United Kingdom, 2013. Emerg Infect Dis. 2015;21(8):1396-401. https://doi.org/10.3201/eid2108.141995 PMID: 26196216

12. Crossan C, Grierson S, Thomson J, Ward A, Nunez-Garcia J, Banks M, et al. Prevalence of hepatitis E virus in slaughterage pigs in Scotland. Epidemiol Infect. 2015;143(10):2237-40. https://doi.org/10.1017/So950268814003100 PMID: 25410494

13. Feurer C, Le Roux A, Rossel R, Barnaud E, Dumarest M, Garry $P$, et al. High load of hepatitis $E$ viral RNA in pork livers but absence in pork muscle at French slaughterhouses. Int Food Microbiol. 2018;264:25-30. https://doi.org/10.1016/j. ijfoodmicro.2017.10.013 PMID: 29107193

14. Hummel KB, Lowe L, Bellini WJ, Rota PA. Development of quantitative gene-specific real-time RT-PCR assays for the detection of measles virus in clinical specimens. J Virol Methods. 2006;132(1-2):166-73. https://doi.org/10.1016/j. jviromet.2005.10.006 PMID: 16274752

15. Huang FF, Haqshenas G, Guenette DK, Halbur PG, Schommer SK, Pierson FW, et al. Detection by reverse transcription-PCR and genetic characterization of field isolates of swine hepatitis E virus from pigs in different geographic regions of the United States. J Clin Microbiol. 2002;40(4):1326-32. https://doi. org/10.1128/JCM.40.4.1326-1332.2002 PMID: 11923352

16. Boxman ILA, Jansen CCC, Hägele G, Zwartkruis-Nahuis A, Cremer J, Vennema H, et al. Porcine blood used as ingredient in meat productions may serve as a vehicle for hepatitis $E$ virus transmission. Int J Food Microbiol. 2017;257:225-31. https:// doi.org/10.1016/j.ijfoodmicro.2017.06.029 PMID: 28692890

17. Smith DB, Simmonds P, Izopet J, Oliveira-Filho EF, Ulrich RG, Johne $R$, et al. Proposed reference sequences for hepatitis $E$ virus subtypes. J Gen Virol. 2016;97(3):537-42. https://doi. org/10.1099/jgv.0.000393 PMID: 26743685

18. Tamura K, Peterson D, Peterson N, Stecher G, Nei M, Kumar S. MEGA5: molecular evolutionary genetics analysis using maximum likelihood, evolutionary distance, and maximum parsimony methods. Mol Biol Evol. 2011;28(10):2731-9. https://doi.org/10.1093/molbev/msr121 PMID: 21546353

19. van der Poel WH, Verschoor F, van der Heide R, Herrera MI, Vivo $A$, Kooreman $M$, et al. Hepatitis $E$ virus sequences in swine related to sequences in humans, The Netherlands. Emerg Infect Dis. 2001;7(6):970-6. https://doi.org/10.3201/ eido706.010608 PMID: 11747723

20. Adlhoch C, Avellon A, Baylis SA, Ciccaglione AR, Couturier $E$, de Sousa R, et al. Hepatitis E virus: Assessment of the epidemiological situation in humans in Europe, 2014/15. J Clin Virol. 2016;82:9-16. https://doi.org/10.1016/j.jcv.2016.06.010 PMID: 27393938

21. Aspinall EJ, Couturier E, Faber M, Said B, ljaz S, Tavoschi $L$, et al. Hepatitis E virus infection in Europe: surveillance and descriptive epidemiology of confirmed cases, 2005 to 2015. Euro Surveill. 2017;22(26): 30561. https://doi. org/10.2807/1560-7917.ES.2017.22.26.30561 PMID: 28681720

22. Faber M, Willrich N, Schemmerer M, Rauh C, Kuhnert R, Stark $\mathrm{K}$, et al. Hepatitis E virus seroprevalence, seroincidence and seroreversion in the German adult population. J Viral Hepat. 2018;25(6):752-8. https://doi.org/10.1111/jvh.12868 PMID: 29377436

23. Mansuy JM, Gallian P, Dimeglio C, Saune K, Arnaud C, Pelletier $B$, et al. A nationwide survey of hepatitis $E$ viral infection in French blood donors. Hepatology. 2016;63(4):1145-54. https:// doi.org/10.1002/hep.28436 PMID: 27008201

24. ljaz S, Said B, Boxall E, Smit E, Morgan D, Tedder RS. Indigenous hepatitis E in England and wales from 2003 to 2012: evidence of an emerging novel phylotype of viruses. J Infect Dis. 2014;209(8):1212-8. https://doi.org/10.1093/infdis/ jit652 PMID: 24273173

25. Said B, Ijaz S, Chand MA, Kafatos G, Tedder R, Morgan D. Hepatitis E virus in England and Wales: indigenous infection is associated with the consumption of processed pork products. Epidemiol Infect. 2014;142(7):1467-75. https://doi.org/10.1017/ So950268813002318 PMID: 24054519

26. Said B, Usdin M, Warburton F, ljaz S, Tedder RS, Morgan D. Pork products associated with human infection caused by an emerging phylotype of hepatitis E virus in England and Wales. Epidemiol Infect. 2017;145(12):2417-23. https://doi. org/10.1017/S0950268817001388 PMID: 28756783

27. Mykytczuk O, Harlow J, Bidawid S, Corneau N, Nasheri N. Prevalence and molecular characterization of the hepatitis $E$ virus in retail pork products marketed in Canada. Food Environ Virol. 2017;9(2):208-18. https://doi.org/10.1007/s12560-0179281-9 PMID: 28197972

\section{License, supplementary material and copyright}

This is an open-access article distributed under the terms of the Creative Commons Attribution (CC BY 4.0) Licence. You may share and adapt the material, but must give appropriate credit to the source, provide a link to the licence and indicate if changes were made.

Any supplementary material referenced in the article can be found in the online version.

This article is copyright of the authors or their affiliated institutions, 2019. 